\title{
ANALISIS PERGESERAN SEKTOR PERTANIAN DI KABUPATEN LANGKAT PROVINSI SUMATERA UTARA
}

\author{
Rahmanta \\ Jurusan Agribisnis Fakultas Pertanian \\ Universitas Sumatera Utara \\ Hp : 081319035250, Email: rahmantaginting@yahoo.com
}

\begin{abstract}
Principally the sectoral shift and development in a region is a sustainable activity to realize a good condition collectively and continuously. The objective of this research is to analyze the change and shift of agricultural sector to the local economic condition in Regency of Langkat. The data applied in this research is secondary data collected from any institution/organization related to the studied problem since 2007 up to 2012. The applied data analysis method is Shift Share Analysis. This method is applied to observe the economic structure and its shift by focus to sectoral development in region than the same one in the higher regional level or in national level. The results of research indicates that (a) agricultural sector is a sector with the bigger role in the Gross Regional Domestic Product (GRDP) of Langkat regency, (b) the national share value for agricultural sector and industry with a rapid growth than the other sectors, $(c)$ the value of differential shift, agricultural sector, industry, electricity and gas, building, transportation and financial is a sector with higher competitive or sector with the rapid shift growth than other sector, and (d) the results of shift share analysis indicates that there is development of GRDP for 93.50 percent.
\end{abstract}

Key words: GRDP, sectoral shift, the development of production sector and shift share analysis

\section{PENDAHULUAN}

$\mathrm{P}$

ada hakekatnya, pembangunan ekonomi adalah serangkaian usaha dan kebijaksanaan yang bertujuan untuk meningkatkan taraf hidup masyarakat, memperluas lapangan kerja, memeratakan pembagian pendapatan masyarakat, meningkatkan hubungan ekonomi regional dan mengusahakan pergeseran kegiatan ekonomi dari sektor primer ke sektor sekunder dan tersier.

QE Journal |Vol.03 - No.03 September 2014 - 147 
Pembangunan ekonomi suatu daerah pada hakekatnya merupakan suatu rangkaian kegiatan yang dilaksanakan secara sadar dan terus menerus untuk mewujudkan keadaan yang lebih baik secara bersama-sama dan berkesinambungan. Dalam kerangka itu, pembangunan ekonomi juga ditujukan untuk memacu pemerataan pembangunan dan hasil-hasilnya dalam rangka meningkatkan kesejahteraan rakyat secara adil dan merata. Salah satu indikator yang biasanya digunakan untuk mengukur pembangunan ekonomi yang terjadi pada suatu daerah adalah pertumbuhan ekonomi. Walaupun indikator ini mengukur tingkat pertumbuhan output dalam suatu perekonomian, namun sesungguhnya juga memberikan indikasi tentang sejauhmana aktivitas perekonomian yang terjadi pada suatu periode tertentu telah menghasilkan peningkatan pendapatan bagi masyarakat.

Suatu perekonomian dikatakan mengalami pertumbuhan atau perkembangan jika tingkat kegiatan ekonominya meningkat atau lebih tinggi jika dibandingkan dengan tahun sebelumnya. Dengan kata lain, perkembangannya baru terjadi jika jumlah barang dan jasa secara fisik yang dihasilkan perekonomian tersebut bertambah besar pada tahun-tahun berikutnya.

Transformasi sektoral pertama kali diperkenalkan Fisher pada tahun 1935, Fisher mengenalkan konsep tentang kegiatan primer, sekunder dan tersier. Sektor primer sebagai kegiatan pertanian dan produksi perkebunan, serta beberapa kasus dalam kegiatan pertambangan. Sektor sekunder terdiri dari kegiatan manufaktur dan konstruksi. Sektor tersier terdiri dari transportasi dan komunikasi, perdagangan, pemerintahan dan jasa lainnya (Jhingan, 2008).

Menurut Todaro (1997), tingkat perubahan struktural dan pertumbuhan sektoral yang tinggi melekat dalam proses pertumbuhan dan sebagian komponen pertumbuhan struktur tersebut mencakup pergeseran berangsur-angsur dari aktivitas pertanian ke sektor non pertanian, bahkan dari sektor industri ke jasa. Pergeseran ini dapat dilihat dari perannya terhadap peningkatan produksi maupun tenaga kerja dan kontribusi dalam pembentukan Pendapatan Domestik Regional Bruto.

Kuznets, perubahan struktur ekonomi atau transformasi struktural ditandai oleh perubahan persentase sumbangan berbagai sektor dalam 
pembangunan ekonomi yang disebabkan intensitas manusia dan perubahan teknologi secara umum (Sukirno, 1985).

Djojohadikusumo (1994), mengatakan bahwa perubahan struktural biasanya ditandai dengan peralihan dan pergeseran dari kegiatan sektor produksi primer (pertanian dan pertambangan) ke sektor produksi sekunder (industri manufaktur dan konstruksi), dan sektor tersier (jasajasa).

Pemerintah Daerah perlu membuat prioritas kebijakan agar pembangunan daerah dapat berjalan sesuai rencana. Terkait dengan kebijakan anggaran, penentuan prioritas kebijakan tentang pengeluaran daerah merupakan hal yang penting. Penentuan prioritas kebijakan tersebut dapat diwujudkan salah satunya dengan menentukan sektor-sektor prioritas atau unggulan. Lebih jauh, penentuan prioritas tidak hanya dilakukan pada tingkat sektoral saja, tetapi juga pada tingkat usaha, bahkan tingkat komoditi yang layak untuk dikembangkan sesuai dengan kebutuhan dan potensi yang ada.

Pembangunan daerah yang terdesentralisasi memberikan kesempatan kepada daerah untuk merencanakan pembangunan sesuai kebutuhan berdasarkan karakteristik yang spesifik dan potensi-potensi sumberdaya daerah yang tersedia. Perencanaan pembangunan daerah didefinisikan sebagai suatu usaha yang sistematis dari berbagai pelaku yaitu pemerintah, swasta atau kelompok masyarakat lainnya pada berbagai tingkatan untuk menghadapinya saling ketergantungan dan keterkaitan aspek-aspek fisik, sosial-ekonomi serta aspek lingkungan lainnya dengan cara : (1) secara terus menerus menganalisis kondisi dan pelaksanaan pembangunan daerah; (2) merumuskan tujuan-tujuan dan kebijakan pembangunan daerah; (3) menyusun konsep-konsep strategi bagi pemecahan masalah (solusi) dan (4) melaksanakannya sesuai dengan sumber daya yang tersedia. Dengan demikian, peluang-peluang baru untuk meningkatkan kesejahteraan daerah dapat ditangkap secara berkelanjutan.

Perencanaan pembangunan di Kabupaten Langkat perlu memiliki data dan informasi yang memadai sebagai dasar dalam pengambilan kebijakan, maka para perencana pembangunan daerah harus dapat menganalisis, menjelaskan dan memahami tentang kegiatan ekonomi potensial atau sektor yang mampu memacu pertumbuhan ekonomi serta struktur dan 
pola ekonomi daerah, sehingga pendekatan pelaksanaan pembangunan daerah di Kabupaten Langkat dengan pengembangan wilayah berdasarkan keunggulannya dan pergeseran sektor ekonomi sehingga dapat menciptakan keserasian pertumbuhan ekonomi. Informasi yang perlu diketahui terkait dengan analisis diatas adalah peran sektor dalam menyumbangkan output di daerah dan perkembangannya dapat dilihat dari pertumbuhan ekonomi atau Produk Domestik Regional Bruto.

Berdasarkan latar belakang di atas maka tujuan penelitian ini adalah untuk menganalisis perubahan dan pergeseran sektor pertanian pada perekonomian daerah di Kabupaten Langkat.

\section{METODE PENELITIAN}

Ruang lingkup penelitian ini adalah menganalisis perkembangan suatu sektor ekonomi di suatu daerah jika dibandingkan dengan sektor-sektor lainnya, apakah tumbuh dengan cepat atau lambat, khususnya di Kabupaten Langkat Provinsi Sumatera Utara.

Data yang digunakan dalam penelitian ini adalah data sekunder yang dikumpulkan dari berbagai instansi/lembaga yang terkait dengan permasalahan yang sedang diteliti, yaitu Badan Pusat Statistik (BPS) Provinsi Sumatera Utara dan Badan Pusat Statistik (BPS) Kabupaten Langkat, Bappeda dan instansi terkait lainnya. Data yang digunakan mulai tahun 2007 sampai dengan tahun 2012.

Analisis Shift Share membandingkan perbedaan laju pertumbuhan berbagai sektor (industri) di daerah kita dengan nasional. Metode ini memperinci penyebab perubahan atas beberapa variabel. Analisis ini menggunakan metoda pengisolasian berbagai faktor yang menyebabkan perubahan struktur sektor suatu daerah dalam pertumbuhannya dari satu kurun waktu ke kurun waktu berikutnya. Hal ini meliputi penguraian faktor penyebab pertumbuhan berbagai sektor di suatu daerah tetapi dalam kaitannya dengan ekonomi nasional. Ada juga yang menamakan model analisis ini sebagai industrial mix analysis, karena komposisi industri yang ada sangat mempengaruhi laju pertumbuhan wilayah tersebut. Analisis Shift Share dapat menggunakan variabel lapangan kerja atau nilai tambah (PDRB). Dalam penelitian ini menggunakan data PDRB di Kabupaten Langkat dan Provinsi Sumatera Utara. 
Pertambahan PDRB regional total $\left(\triangle \mathrm{PDRB}_{\mathrm{t}}\right)$ dapat diurai menjadi komponen shift dan komponen share. Komponen share sering pula disebut komponen national share. Komponen national share $(\mathrm{N})$ adalah banyaknya pertambahan PDRB regional seandainya proporsi perubahannya sama dengan laju pertambahan nasional selama periode studi. Hal ini dapat dipakai sebagai kriteria bagi daerah yang bersangkutan untuk mengukur apakah daerah itu tumbuh lebih cepat atau lebih lambat dari pertumbuhan rata-rata nasional. Komponen shift adalah penyimpangan (deviation) dari national share dalam pertumbuhan PDRB regional. Penyimpangan ini positif didaerah-daerah yang tumbuh lebih cepat dan negatif didaerah-daerah yang tumbuh lebih lambat/merosot dibandingkan dengan pertumbuhan PDRB secara nasional.

Dengan menggunakan notasi aljabar, berbagai hubungan antara komponen-komponen di atas dapat dinyatakan pada uraian berikut ini. Akan tetapi, sebelum mengemukakan rumus hubungan terlebih dahulu akan dikemukakan notasi yang digunakan sebagai berikut :

$\Delta$ : Pertambahan angka akhir (tahun $\mathrm{t}$ ) dikurangi dengan angka awal (tahun $\mathrm{t}-\mathrm{n}$ ); $\mathrm{N}$ : Wilayah nasional yang lebih tinggi jenjangnya; $\mathrm{r}$ : Region atau daerah analisis; E: Banyaknya lapangan kerja atau nilai PDRB; i : Sektor ekonomi; t: Tahun; t-1: Tahun awal; Ns : National share; Pr: Proportional share; Dr : Differential shift.

Hubungan antara kompoenen tersebut dapat diuraikan sebagai berikut :

$$
\Delta \mathrm{Er}=\mathrm{Er}, \mathrm{t}-\mathrm{Er} \mathrm{t}-\mathrm{n}
$$

Artinya, pertambahan PDRB regional adalah banyaknya PDRB pada tahun akhir (t) dikurangi dengan jumlah PDRB pada tahun awal (t-n).

Persamaan di atas berlaku untuk total PDRB di daerah tersebut. Hal ini dapat juga dilihat secara per sektor sebagai berikut:

$$
\Delta \text { Eri }=\text { Er,i.t }-\mathrm{Er}, \mathrm{i}, \mathrm{t}-\mathrm{n}
$$

Artinya pertambahan PDRB regional sektor i adalah jumlah PDRB sektor i pada tahun akhir $(t)$ dikurangkan dengan PDRB sektor i pada tahun awal $(t-n)$. Pertambahan PDRB regional sektor $i$ ini dapat diperinci atas pengaruh dari National share, Proportional share dan Differential shift. Dalam notasi aljabar hal itu adalah: 


$$
\Delta \mathrm{Er}, \mathrm{i}, \mathrm{t}=(\mathrm{Nsi}+\mathrm{Pr}, \mathrm{i}+\mathrm{Dr}, \mathrm{i})
$$

Peranan National share adalah seandainya pertambahan PDRB regional sektor i tersebut sama dengan proporsi pertambahan PDRB nasional secara rata-rata. Hal ini dapat ditulis sebagai berikut :

$$
\mathrm{Ns}, \mathrm{i}, \mathrm{t}=\mathrm{Er}, \mathrm{i}, \mathrm{t}-\mathrm{n}(\mathrm{EN}, \mathrm{t} / \mathrm{EN}, \mathrm{t}-\mathrm{n})-\mathrm{Er}, \mathrm{i}, \mathrm{t}-\mathrm{n}
$$

Proportional share adalah melihat pengaruh sektor i secara nasional terhadap pertumbuhan PDRB sektor i pada region yang dianalisis. Hal ini dapat dituliskan sebagai berikut :

$$
\operatorname{Pr}, \mathrm{i}, \mathrm{t}=\{\mathrm{EN}, \mathrm{i}, \mathrm{t} / \mathrm{EN}, \mathrm{i}, \mathrm{t}-\mathrm{n})-(\mathrm{EN}, \mathrm{t} / \mathrm{EN}, \mathrm{t}-\mathrm{n})\} \times \mathrm{Er}, \mathrm{i}, \mathrm{t}-\mathrm{n}
$$

Differential shift menggambarkan penyimpangan antar pertumbuhan sektor i di wilayah analisis terhadap pertumbuhan sektor i secara nasional. Hal ini dapat dituliskan sebagai berikut.

$$
\operatorname{Dr}, \mathrm{i}, \mathrm{t}=\{\mathrm{Er}, \mathrm{i}, \mathrm{t}-(\mathrm{EN}, \mathrm{i}, \mathrm{t} / \mathrm{EN}, \mathrm{i}, \mathrm{t}-\mathrm{n}) \mathrm{Er}, \mathrm{i}, \mathrm{t}-\mathrm{n}\}
$$

Perlu diingat bahwa apabila kita hendak melihat pengaruhnya terhadap seluruh daerah analisis maka angka untuk masing-masing sektor harus ditambahkan. Persamaan untuk seluruh daerah adalah sebagai berikut.

$$
\Delta \mathrm{Er}=(\mathrm{Ns}+\mathrm{Pr}+\mathrm{Dr})
$$

Dimana:

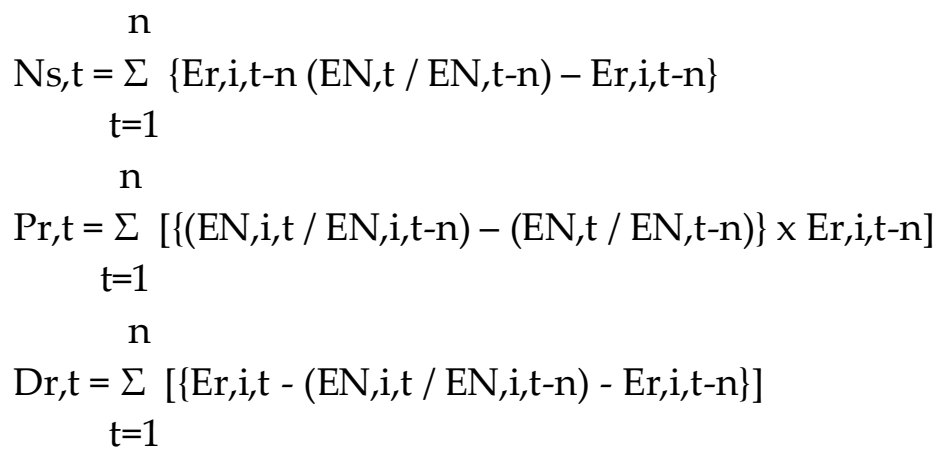




\section{HASIL DAN PEMBAHASAN}

\section{Peranan atau kontribsui Sektor Pertanian}

Peranan atau kontribusi sektor-sektor menunjukkan struktur perekonomian yang terbentuk di suatu daerah. Struktur ekonomi ini menunjukkan besarnya kemampuan masing-masing sektor dalam menciptakan nilai tambah, sekaligus menggambarkan ketergantungan daerah terhadap kemampuan memproduksi barang dan jasa dari masingmasing sektor. Pergeseran struktur ini sering dipakai sebagai indikator untuk menunjukkan adanya suatu proses pembangunan.

Untuk mengetahui gambaran tentang struktur perekonomian suatu daerah dapat dilihat dari persentase sektoral PDRB yang dirinci menurut lapangan usaha. Sektor tersebut dibagi 3 sektor utama yaitu sektor primer, sektor sekunder dan sektor tersier. Sektor primer mencakup kegiatan pertanian dan penggalian. Sektor sekunder meliputi industri pengolahan, listrik, gas dan air bersih serta bangunan. Sektor tersier meliputi perdagangan, hotel dan restoran, pengangkutan dan komunikasi, keuangan, jasa perusahaan, persewaan bangunan dan jasa-jasa lainnya.

Secara umum ada empat kegiatan ekonomi yang cukup dominan dalam pembentukan total PDRB Kabupaten Langkat yaitu sektor pertanian, sektor industri pengolahan, sektor perdagangan, hotel dan restoran, serta sektor pertambangan, dan penggalian. Sedangkan kegiatan ekonomi lain secara berurutan sesuai dengan peranannya terhadap pembentukan total nilai PDRB adalah jasa-jasa, pengangkutan dan komunikasi, bangunan, keuangan, persewaan dan jasa perusahaan serta listrik, gas dan air bersih. Perkembangan distribusi PDRB Kabupaten Langkat dapat diuraikan pada Tabel 1.

Berdasarkan Tabel 1, bahwa seperti tahun-tahun sebelumnya sektor pertanian merupakan sektor yang paling besar peranannya terhadap pembentukan PDRB Kabupaten Langkat. Pada tahun 2012 sektor pertanian sebesar 49,85 persen, kemudian disusul sektor Industri pengolahhan sebesar 12,96 persen, sektor perdagangan, hotel dan restoran sebesar 10,97 persen, sektor pertambangan dan penggalian sebesar 10,62 persen, sektor jasa-jasa 7,00 persen, sektor bangunan 3,19 persen, sektor pengangkutan dan komunikasi 2,83 persen, sektor keuangan 2,03 persen dan sektor listrik, gas dan air bersih sebesar 0,54 persen.

QE Journal | Vol.03 - No.03 September 2014 - 153 
Tabel 1. Distribusi PDRB Kabupaten Langkat Menurut Lapangan Usaha Tahun 2008 - 2012 (Persen)

\begin{tabular}{clccccc}
\hline \multirow{2}{*}{ No } & \multirow{2}{*}{ Lapangan Usaha } & \multicolumn{5}{c}{ T a h u n } \\
\cline { 3 - 6 } & & 2008 & 2009 & 2010 & 2011 & 2012 \\
\hline 1 & Pertanian & 48,70 & 49,15 & 49,27 & 49,53 & 49,85 \\
2 & Pertambangan, Galian & 11,57 & 11,34 & 11,19 & 11,19 & 10,62 \\
3 & Industri Pengolahan & 14,09 & 13,79 & 13,54 & 13,13 & 12,96 \\
4 & Listrik, Gas, Air bersih & 0,56 & 0,56 & 0,54 & 0,53 & 0,54 \\
5 & Bangunan & 2,59 & 2,67 & 2,73 & 2,86 & 3,19 \\
6 & Perdagangan, hotel dan restoran & 11,42 & 11,16 & 11,27 & 11,08 & 10,97 \\
7 & Pengangkutan \& Komunikasi & 2,75 & 2,79 & 2,82 & 2,78 & 2,83 \\
8 & Keuangan, sewa dan jasa perusahaan & 1,80 & 1,89 & 1,91 & 1,93 & 2,03 \\
9 & Jasa-jasa & 6,53 & 6,65 & 6,73 & 6,96 & 7,00 \\
& PDRB & 100,00 & 100,00 & 100,00 & 100,00 & 100,00 \\
\hline
\end{tabular}

Sumber : Badan Pusat Statistik Kabupaten Langkat, 2013.

\section{Analisis Shift Share}

Analisis shift share menganalisis perubahan berbagai indikator kegiatan ekonomi, seperti kesempatan kerja, nilai PDRB pada dua titik waktu di suatu daerah. Dari hasil analisis ini akan diketahui bagaimana perkembangan suatu sektor di suatu daerah jika dibandingkan dengan sektor-sektor lainnya, apakah tumbuh dengan cepat atau lambat. Hasil analisis ini juga dapat menunjukkan bagaimana perkembangan suatu daerah dibandingkan dengan daerah lainnya, apakah bertumbuh dengan cepat atau lambat. Dalam analisis ini diasumsikan bahwa perubahan nilai PDRB di suatu daerah antara tahun dasar dengan tahun akhir analisis dibagi menjadi tiga kompenen yaitu : (1) komponen nasional share (Ns), (2) komponen proporsional share (Pr), dan (3) komponen differensial shift (Dr). Hasil analisis ketiga komponen tersebut akan diuraikan sebagai berikut.

Tabel 2. Analisis PDRB Kabupaten Langkat dan Sumatera Utara Dengan Metoda Shift Share

\begin{tabular}{llcccc}
\hline & & \multicolumn{2}{c}{ Langkat } & \multicolumn{2}{c}{ Sumatera Utara } \\
\cline { 3 - 6 } No & \multirow{2}{*}{ Sektor } & 2007 & 2012 & 2007 & 2012 \\
\cline { 3 - 6 } & & (a) & (b) & (c) & $(\mathrm{d})$ \\
\cline { 3 - 6 } & & Er,i,t-n & Er,i,t & EN,i,t-n & EN,i,t \\
1 & Pertanian & 5590521.00 & 11050791.99 & 41010150.00 & 76838110.00 \\
2 & Perrtambangan & 1380158.87 & 2354943.34 & 2404920.00 & 4635320.00 \\
3 & Industri & 1564345.09 & 2872887.26 & 45531180.00 & 77484960.00 \\
\hline
\end{tabular}

QE Journal |Vol.03 - No.03 September 2014 - 154 


\begin{tabular}{rlrrrr}
\hline 4 & Listrik, Gas & 59248.51 & 118690.25 & 1897560.00 & 3178780.00 \\
5 & Bangunan & 292600.17 & 707601.50 & 10548460.00 & 23595940.00 \\
6 & Perdagangan & 1329538.05 & 2432003.39 & 34846210.00 & 67027280.00 \\
7 & Pengangkutan & 310235.47 & 626904.63 & 16363680.00 & 32854360.00 \\
8 & Keuangan & 195052.29 & 450623.79 & 11587850.00 & 26442210.00 \\
9 & Jasa-jasa & 733619.41 & 1552050.36 & 17629720.00 & 39061180.00 \\
& PDRB & $11,455,318.86$ & $22,166,496.51$ & 181819730.00 & 351118140.00 \\
\hline
\end{tabular}

Sumber: Badan Pusat Statistik Sumatera Utara, 2014

Tabel 3a. Perhitungan National Share

\begin{tabular}{|c|c|c|c|c|c|}
\hline \multirow{4}{*}{ No } & \multirow{4}{*}{ Sektor } & \multicolumn{2}{|c|}{ Langkat } & \multicolumn{2}{|c|}{ Sumatera Utara } \\
\hline & & 2007 & 2012 & 2007 & 2012 \\
\hline & & (a) & (b) & (c) & (d) \\
\hline & & Er,i,t-n & $\mathrm{Er}, \mathrm{i}, \mathrm{t}$ & EN,i,t-n & $\mathrm{EN}, \mathrm{i}, \mathrm{t}$ \\
\hline 1 & Pertanian & 5590521.00 & 11050791.99 & 41010150.00 & 76838110.00 \\
\hline 2 & Perrtambangan & 1380158.87 & 2354943.34 & 2404920.00 & 4635320.00 \\
\hline 3 & Industri & 1564345.09 & 2872887.26 & 45531180.00 & 77484960.00 \\
\hline 4 & Listrik, Gas & 59248.51 & 118690.25 & 1897560.00 & 3178780.00 \\
\hline 5 & Bangunan & 292600.17 & 707601.50 & 10548460.00 & 23595940.00 \\
\hline 6 & Perdagangan & 1329538.05 & 2432003.39 & 34846210.00 & 67027280.00 \\
\hline 7 & Pengangkutan & 310235.47 & 626904.63 & 16363680.00 & 32854360.00 \\
\hline 8 & Keuangan & 195052.29 & 450623.79 & 11587850.00 & 26442210.00 \\
\hline \multirow[t]{2}{*}{9} & Jasa-jasa & 733619.41 & 1552050.36 & 17629720.00 & 39061180.00 \\
\hline & PDRB & $11,455,318.86$ & $22,166,496.51$ & 181819730.00 & 351118140.00 \\
\hline
\end{tabular}

Sumber : Badan Pusat Statistik Sumatera Utara, Diolah, 2014

Tabel 3b. Lanjutan Perhitungan National Share

\begin{tabular}{rrr}
\hline \multicolumn{1}{c}{$(\mathrm{e})$} & $(\mathrm{f})$ & $\mathrm{f}-\mathrm{a}$ \\
\hline$\sum \mathrm{EN}, \mathrm{i}, \mathrm{t} / \sum \mathrm{EN}, \mathrm{I}, \mathrm{t}-\mathrm{n}$ & $\mathrm{a} \times \mathrm{e})$ & $\mathrm{Ns}$ \\
\hline 1.9312 & 10796414.16 & 5205893.16 \\
1.9312 & 2665362.81 & 1285203.94 \\
1.9312 & 3021063.24 & 1456718.15 \\
1.9312 & 114420.72 & 55172.21 \\
1.9312 & 565069.45 & 272469.28 \\
1.9312 & 2567603.88 & 1238065.83 \\
1.9312 & 599126.74 & 288891.27 \\
1.9312 & 376684.98 & 181632.69 \\
1.9312 & 1416765.80 & 683146.39 \\
& & 10667192.92 \\
\hline
\end{tabular}

QE Journal | Vol.03 - No.03 September 2014 - 155 
Tabel 4. Perhitungan Proporsional Share

\begin{tabular}{|c|c|c|c|c|c|c|}
\hline \multirow{3}{*}{ No } & \multirow{3}{*}{ Sektor } & Langkat & \multicolumn{2}{|c|}{ Sumatera Utara } & \multirow[b]{2}{*}{$b-c$} & \multirow[b]{2}{*}{ Ps } \\
\hline & & 2007 & $\begin{array}{c}\text { EN,i,t/ } \\
\text { EN,i,t-n }\end{array}$ & $\begin{array}{c}\sum \mathrm{EN}, \mathrm{i}, \mathrm{t} / \\
\sum \mathrm{EN}, \mathrm{i}, \mathrm{t}-\mathrm{n}\end{array}$ & & \\
\hline & & (a) & (b) & (c) & $(\mathrm{d})$ & $a \times d$ \\
\hline 1 & Pertanian & 5590521.00 & 1.8736 & 1.9312 & -0.0576 & -321810.49 \\
\hline 2 & Pertambangan & 1380158.87 & 1.9274 & 1.9312 & -0.0038 & -5200.30 \\
\hline 3 & Industri & 1564345.09 & 1.7018 & 1.9312 & -0.2294 & -358860.84 \\
\hline 4 & Listrik, Gas & 59248.51 & 1.6752 & 1.9312 & -0.2560 & -15168.01 \\
\hline 5 & Bangunan & 292600.17 & 2.2369 & 1.9312 & 0.3057 & 89450.36 \\
\hline 6 & Perdagangan & 1329538.05 & 1.9235 & 1.9312 & -0.0077 & -10214.74 \\
\hline 7 & Pengangkutan & 310235.47 & 2.0078 & 1.9312 & 0.0766 & 23751.97 \\
\hline 8 & Keuangan & 195052.29 & 2.2819 & 1.9312 & 0.3507 & 68403.07 \\
\hline 9 & Jasa-jasa & 733619.41 & 2.2156 & 1.9312 & 0.2844 & 208673.50 \\
\hline & PDRB & $11,455,318.86$ & & & & $-320,975.48$ \\
\hline
\end{tabular}

Sumber : Badan Pusat Statistik Sumatera Utara, Diolah, 2014

Tabel 5. Perhitungan Differential Shift

\begin{tabular}{|c|c|c|c|c|c|c|}
\hline \multirow{3}{*}{ No } & \multirow{3}{*}{ Sektor } & \multicolumn{2}{|c|}{ Langkat } & \multicolumn{2}{|c|}{ Langkat } & \multirow{2}{*}{$\begin{array}{l}\text { Ds } \\
\mathrm{a}-\mathrm{d}\end{array}$} \\
\hline & & \multirow{2}{*}{$\begin{array}{c}2012 \\
\text { (a) }\end{array}$} & $\begin{array}{l}\text { EN,i,t/ } \\
\text { EN,i,t- } \\
n\end{array}$ & \multirow{2}{*}{$\begin{array}{l}2007 \\
\text { (c) }\end{array}$} & \multirow{2}{*}{$\frac{\mathrm{b} \times \mathrm{c}}{\mathrm{D}}$} & \\
\hline & & & (b) & & & $\mathrm{E}$ \\
\hline 1 & Pertanian & 11050791.99 & 1.8736 & 5590521.00 & 10474603.67 & 576188.32 \\
\hline 2 & Pertambangan & 2354943.34 & 1.9274 & 1380158.87 & 2660162.51 & -305219.17 \\
\hline 3 & Industri & 2872887.26 & 1.7018 & 1564345.09 & 2662202.40 & 210684.86 \\
\hline 4 & Listrik, Gas & 118690.25 & 1.6752 & 59248.51 & 99252.71 & 19437.54 \\
\hline 5 & Bangunan & 707601.50 & 2.2369 & 292600.17 & 654519.81 & 53081.69 \\
\hline 6 & Perdagangan & 2432003.39 & 1.9235 & 1329538.05 & 2557389.14 & -125385.75 \\
\hline 7 & Pengangkutan & 626904.63 & 2.0078 & 310235.47 & 622878.71 & 4025.92 \\
\hline 8 & Keuangan & 450623.79 & 2.2819 & 195052.29 & 445088.05 & 5535.74 \\
\hline 9 & Jasa-jasa & 1552050.36 & 2.2156 & 733619.41 & 1625439.31 & -73388.95 \\
\hline & PDRB & $22,166,496.51$ & & $11,455,318.86$ & & $364,960.20$ \\
\hline
\end{tabular}

Sumber : Badan Pusat Statistik Sumatera Utara, Diolah, 2014 
Tabel 6. Analisis Pergeseran Sektoral di Kabupaten Langkat, Tahun 2007 2012

\begin{tabular}{llrrrr}
\hline No & \multicolumn{1}{c}{ Sektor } & $\begin{array}{c}\text { Komponen } \\
\text { Nasional }\end{array}$ & $\begin{array}{c}\text { Proposional } \\
\text { Share }\end{array}$ & $\begin{array}{c}\text { Differential } \\
\text { Shift }\end{array}$ & $\begin{array}{c}\text { Pergeseran } \\
\text { Sektoral }\end{array}$ \\
\hline 1 & Pertanian & $5,205,893.16$ & -321810.49 & $576,188.32$ & $5,460,270.99$ \\
2 & Pertambangan & $1,285,203.94$ & -5200.30 & $-305,219.17$ & $974,784.47$ \\
3 & Industri & $1,456,718.15$ & -358860.84 & $210,684.86$ & $1,308,542.17$ \\
4 & Listrik, Gas & $55,172.21$ & -15168.01 & $19,437.54$ & $59,441.74$ \\
5 & Bangunan & $272,469.28$ & 89450.36 & $53,081.69$ & $415,001.33$ \\
6 & Perdagangan & $1,238,065.83$ & -10214.74 & $-125,385.75$ & $1,102,465.34$ \\
7 & Pengangkutan & $288,891.27$ & 23751.97 & $4,025.92$ & $316,669.16$ \\
8 & Keuangan & $181,632.69$ & 68403.07 & $5,535.74$ & $255,571.50$ \\
9 & Jasa-jasa & $683,146.39$ & $208,673.50$ & $-73,388.95$ & $818,430.95$ \\
& $\quad$ Jumlah & $10,667,192.92$ & $-320,975.48$ & $364,960.20$ & $10,711,177.65$ \\
\hline
\end{tabular}

Sumber : Badan Pusat Statistik Sumatera Utara, Diolah, 2014

\section{Komponen Nasional Share/Komponen Pertumbuhan Nasional}

Kompoenen nasional share adalah mengkaji perubahan produksi suatu daerah yang disebabkan oleh perubahan produksi nasional secara umum, atau perubahan dalam hal-hal yang mempengaruhi perekonomian semua sektor dan daerah. Bila diasumsikan bahwa tidak terdapat perbedaan karakteristik ekonomi antar sektor produksi dan antar daerah, maka akibat dari perubahan ini pada berbagai sektor produksi dan daerah kurang lebih sama dan setiap sektor dan daerah akan berubah dan bertumbuh dengan laju yang hampir sama dengan laju pertumbuhan nasional. Akan tetapi pada kenyataannya beberapa sektor bertumbuh lebih cepat dari sektorsektor lainnya dan beberapa daerah lebih maju dari pada daerah lainnya. Oleh karena itu perlu identifikasi penyebabnya dan mengukur besaran yang disebabkan oleh komponen nasional share.

Berdasarakan komponen nasional share ternyata sektor yang memiliki pertumbuhan paling cepat di Kabupaten Langkat bila dibandingkan dengan pertumbuhan rata-rata Provinsi Sumatera Utara adalah sektor pertanian yang memiliki nilai komponen nasional share yang paling tinggi dari seluruh sektor produksi yaitu sebesar 5,205,893.16 juta rupiah, kemudian disusul sektor industri yaitu sebesar 1,456,718.15 juta rupiah, kemudian sektor pertambangan sebesar 1,285,203.94 juta rupiah. Sementara 
sektor yang pertumbuhan regionalnya paling lambat yaitu sektor listrik dan gas yaitu sebesar 55,172.21 juta rupiah. Berdasarkan hasil analisis ini maka dapat dikatakan bahwa untuk memacu pertumbuhan ekonomi daerah di Kabupaten Langkat yang lebih tinggi lagi di masa mendatang adalah paling tepat dilaksanakan dengan mendorong sektor prioritas yaitu meliputi sektor pertanian, industri, dan sektor lainnya.

\section{Komponen Proporsional Share/Komponen Pertumbuhan Proporsional}

Berdasarkan hasil analisis komponen proporsional share, bagi sektor yang bertanda positif dapat dikatakan sebagai sektor yang maju, sedangkan sektor yang bertanda negatif sebagai sektor yang tidak maju. Meskipun sektor industri dan pertanian merupakan sektor yang tumbuh dengan cepat, namun berdasarkan hasil proporsional share mengindikasikan bahwa sektor pertanian dan industri di Kabupaten Langkat selama ini bukan merupakan sektor yang maju. Keadaan ini cermin dari nilai komponen proporsional share sektor pertanian yang bertanda negatif yaitu sebesar -321810.49 juta rupiah, begitu juga untuk sektor industri yaitu sebesar -358860.84 juta rupiah merupakan sektor yang belum maju. Sedangkan untuk sektor lainnya, seperti sektor bangunan, pengangkutan dan keuangan serta jasa-jasa merupakan sektor yang maju, karena memiliki nilai proporsional share yang bertanda positif.

\section{Komponen Differensial Shift/Komponen Pertumbuhan Pangsa Wilayah}

Komponen differensial shift timbul karena adanya peningkatan atau penurunan dari PDRB atau nilai sektor produksi dalam suatu daerah dibandingkan dengan daerah lainnya. Cepat atau lambatnya pergeseran sektor suatu daerah dibandingkan dengan daerah lainnya disebabkan oleh keunggulan komparatif, akses ke pasar, prasarana sosial dan ekonomi pada daerah tersebut, dan lainnya.

Berdasarkan hasil analisis differential shift, sektor pertanian, industri, listrik dan gas, bangunan, pengangkutan dan keuangan merupakan sektor yang memiliki daya saing yang tinggi atau sektor yang pertumbuhan pergeseran yang cepat dibandingkan dengan sektor-sektor lainnya dalam daerahnya sendiri. Situasi ini tercermin dari nilai komponen differential share untuk sektor-sektor tersebut bertanda positif.

Sedangkan sektor lainnya, seperti : sektor pertambangan dan galian, perdagangan dan jasa-jasa merupakan sektor yang memiliki daya saing QE Journal | Vol.03 - No.03 September 2014 - 158 
yang rendah atau sektor yang pertumbuhan pergeseran yang lambat, dibandingkan dengan sektor-sektor lainnya dalam daerahnya sendiri. Situasi ini tercermin dari nilai komponen differential shift untuk sektorsektor tersebut bertanda negatif. Jadi, dapat disimpulkan bahwa peran sektor pertanian masih cukup dominan dalam pembangunan daerah di Kabupaten Langkat.

\section{Pergeseran Struktur Sektor Ekonomi}

Hasil analisis shift share menunjukkan bahwa selama tahun 2007 - 2012, nilai PDRB sektoral Kabupaten Langkat telah mengalami perubahan atau perkembangan. Nilai PDRB tersebut tumbuh sebesar 10,711,177.65 juta rupiah atau sebesar 93,50 persen. Perkembangan tersebut dipengaruhi oleh komponen pertumbuhan nasional, proporsional share dan differential shift.

Dari hasil analisis differential shift dapat disimpulkan bahwa sektor pertanian dan industri merupakan sektor yang tumbuh lebih cepat akibat dari pengaruh perubahan produksi atau kebijakan nasional. Oleh karena itu, strategi ke depan dengan melakukan pembangunan sektor pertanian dan industri yang berkaitan dengan produk-produk pertanian, sehingga diharapkan ke depan terdapat peningkatan sektoral secara menyeluruh dalam suatu daerah.

\section{SIMPULAN DAN SARAN}

\section{Simpulan}

Berdasarkan hasil penelitian maka dapat disimpulkan sebagai berikut :

1. Sektor pertanian merupakan sektor yang paling besar peranannya terhadap pembentukan PDRB Kabupaten Langkat.

2. Nilai nasional share sektor pertanian dan industri memiliki memiliki pertumbuhan paling cepat dibandingkan dengan sektor lainnya.

3. Nilai differential shift, sektor pertanian, industri, listrik dan gas, bangunan, pengangkutan dan keuangan merupakan sektor yang memiliki daya saing yang tinggi atau sektor yang pertumbuhan pergeseran yang cepat dibandingkan dengan sektor lainnya.

QE Journal |Vol.03 - No.03 September 2014 - 159 
Hasil analisis shift share menunjukkan bahwa selama tahun 2007 - 2012, nilai PDRB sektoral Kabupaten Langkat telah mengalami perkembangan. sebesar 10,711,177.65 juta rupiah atau sebesar 93,50 persen.

\section{Saran}

Berdasarkan hasil penelitian dan kesimpulan di atas, maka penulis memberikan beberapa saran, sebagai bentuk implementasi dari hasil penelitian ini yaitu :

1. Hendaknya mempergunakan strategi dan perencanaan yang baik dalam usaha meningkatkan perekonomian Kabupaten Langkat dengan mengembangkan sektor-sektor yang maju sehingga hasil yang diperoleh akan lebih optimal.

2. Hendaknya pengembangan sektor pertanian dan industri dapat ditingkatkan ke depan. Karena sektor ini memiliki nilai pergeseran yang cepat dan sekaligus diarahkan untuk mengatasi masalah pengangguran dan kemiskinan di pedesaan.

\section{DAFTAR PUSTAKA}

Badan Pusat Statistik. 2013. Langkat Dalam Angka 2013. Kabupaten Langkat, Stabat.

Badan Pusat Statistik. 2013. Sumatera Utara Dalam Angka 2013. Provinsi Sumatera Utara, Medan.

Djojohadikusumo, D. 1994. Perkembangan Pemikiran Ekonomi. Yayasan Obor Indonesia, Jakarta.

Ghalib, R. 2005. Ekonomi Regional. Pustaka Ramadhan, Bandung.

Jhingan, M. L, 2008, Ekonomi Pembangunan dan Perencanaan, Edisi Keenambelas, PT. Raja Grafindo Persada, Jakarta.

Mulyanto, H.R. 2008. Prinsip-prinsip Pengembangan Wilayah. Graha Ilmu. Yogyakarta.

Sjafrizal. 2008. Ekonomi Regional : Teori dan Aplikasi. Baduose Media, Sumatera Barat, Padang.

Sugiyono. 2006. Metode Penelitian Administrasi. Alfabeta, Bandung.

Sukirno, S. 1985. Makroekonomi Modern. PT. RajaGrafindo, Jakarta.

QE Journal | Vol.03 - No.03 September 2014 - 160 
Tarigan, R. 2004. Ekonomi Regional : Teori dan Aplikasi. Bumi Aksara, Jakarta.

Todaro, M.P. dan S.C. Smith. 1997. Pembangunan Ekonomi di Dunia Ketiga. Edisi Kedelapan. Erlangga, Jakarta. 